DEPARTMENT OF COMMERCE

BUREAU OF STANDARDS

George K. Burgess, Director

TECHNOLOGIC PAPER OF THE BUREAU OF STANDARDS, No. 269

[Part of Vol. 18]

\title{
SPECIFICATIONS FOR CONSTRUCTING AND OPERATING HEAT-TRANSMISSION APPARATUS FOR TESTING HEAT-INSULATING VALUE OF FABRICS
}

\author{
BY \\ P. D. SALE, Associate Physicist \\ Bureau of Standards
}

December 16, 1924

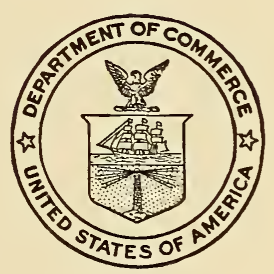

PRICE, 10 CENTS

\$1.25 PER VOLUME ON SUBSCRIPTION

Sold only by the Superintendent of Documents, Government Printing Office Washington, D. C.

WASHINGTON

GOVERNMENT PRINTING OFFICE 
Correct p. 598 , line 13 read" 0.47 ores or $3 / 16$ inch", and p. 604, line S " 4 ," buttom, read " readings markenl $\uparrow$ ' 


\title{
SPECIFICATIONS FOR CONSTRUCTING AND OPERAT- ING HEAT-TRANSMISSION APPARATUS FOR TESTING HEAT-INSULATING VALUE OF FABRICS
}

\author{
By P. D. Sale
}

\begin{abstract}
The information contained herein may be useful to those interested in textile testing, or the building of apparatus for this purpose, others contemplating investigational work in this field, and to the general public who desire information as to how such tests can be made.

This paper is really a supplement to Technologic Paper No. 266, which deals with the general problems of Heat Insulating Properties of Fabrics. Detailed specifications for the construction and operation of an apparatus which has proven satisfactory for this type of test is given herein. Electric wiring diagrams are given for the power and measurement circuits. Instructions and precautions for making measurements and for manipulation are illustrated by a sheet of data and a plot of this for a typical run.
\end{abstract}

\section{CONTENTS}

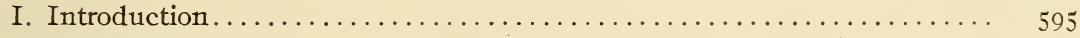

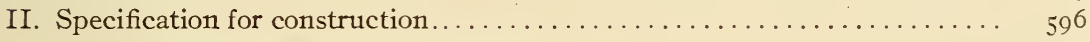

I. Drawings and bill of materials.................... 596

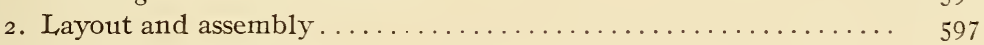

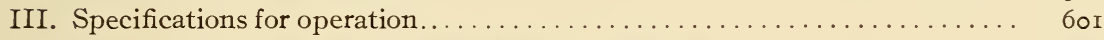

I. Wiring diagram (apparatus and accessories) ............. 6 or

2. Manipulation of power, thermocouple, and potentiometer circuits. $60 \mathrm{I}$

IV. An example of the temperature balance required for tests.......... $60_{3}$

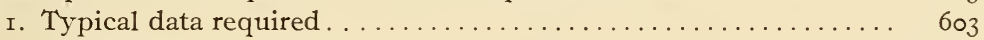

2. Discussion of measurements ...................... 604

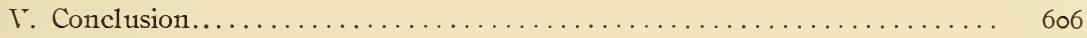

\section{INTRODUCTION}

The purpose of this paper is to supply specifications for the construction and operation of the heat-transmission apparatus developed at the Bureau of Standards for testing the heat-insulating properties of fabrics. The apparatus is believed to be scientifically correct, and an improvement on apparatus used heretofore by other investigators in this field. Its general features could be adopted to advantage in standardizing practice and extending the usefulness of this type of fabric tests. The apparatus herein described may be duplicated and used to advan- 
tage by the textile industry, the trade, or others interested in determinations of heat-insulating value of fabrics.

The general subject has been covered in Bureau of Standards Technologic Paper No. 266, so will not be discussed here.

\section{SPECIFICATION FOR CONSTRUCTION}

\section{DRAWINGS AND BILL OF MATERIALS}

Figure I gives the constructional details, size, shape, and assembly location for the several parts of the apparatus and accessories. In general, the design was controlled by technical considerations of the problems and to gain facility in operation. The itemized description of materials given below enumerates the function of the several parts of the apparatus, and the letters refer to parts as indicated in Figure 5 (cross-sectional assembly).

$A$ Main center heater "Advance" resistance ribbon wound on

$B$ Guard heater $\}$ micanite core.

$C$ Air space (electric and heat insulator).

$D$ Micanite sheets (electric insulator).

$E$ Center copper plates, nickel plated and dull finished (heat distributer).

$E^{\prime}$ Guard copper plates, nickel plated and dull finished (heat distributer).

$f$ Constantan wires, $I, 2$, 3 , etc. (alloy leg of thermocouples).

$g$ Copper wires, $I^{\prime}, 2^{\prime}, 3^{\prime}$, etc. ( $C u$ leg of thermocouple). Other copper wires, $g$, serve as power lead wires.

$H$ Balsa wood mount board (heat and electric insulator).

I Constantan wires (span air space, $c$, and serve as differential thermocouples).

$J$ Steel frame (reinforces edges of the soft mount board, $H$.

$S$ Test specimen (textile material).

$X \mathrm{Cu}$-Const. thermocouple (for determination of temperature at top of specimen).

$Y \mathrm{Cu}$-Const. thermocouple (for determination of temperature at bottom of specimen).

With the materials functioning as illustrated above, the electrical energy supply is uniformly dissipated in the resistance grids, and uniformly distributed over the areas served by the copper plates. The design as shown in the drawings permits separate control of the heat dissipated in the individual heaters, accurate control and measurement of temperatures, generally at 


points on the copper plates, and facility of operation. A bill of materials is given in Figure $I$ and is sufficient to construct one duplex testing set.

\section{LAYOUT AND ASSEMBLY}

(a) LAyouT.-The layout work will be taken up under five separate headings:

I. Center and guard copper plates and thermocouples.-The four copper plates should be laid out accurately in accordance with details shown in Figure I, and each plate marked systematically with identification letters or punch marks to assure best possible fit when the parts are assembled. Cutting the groove to separate the center plate from its guard plate might be done in separate operations on the individual plates, or by one set of operations on the four plates clamped firmly together. This operation can possibly be accomplished best with a good milling cutter whose width is slightly less than the width designated for the slot in Figure I. The plates having been finished accurately to dimensions, they should then be buffed uniformly and nickel plated as soon thereafter as possible to avoid necessity of any further mechanical cleaning. The nickel plate should be left dull for with this finish it is less subject to change.

The thermocouple wires indicated on the drawings should be cut from the same stocks and one extra thermocouple prepared for calibration purposes. The proper number of copper and constantan wires having been cut to the required length, several inches being allowed for connections, they should be given identification numbers because of their several lengths, and soldered at their specified locations on the copper plate. To avoid distortion of the copper plates, which must be kept flat, it was found to be good practice to heat a central and its guard plate together on a uniformly heated hot plate. The one used here for the purpose consisted simply of a ore-directional winding of resistance ribbon on one side only of a three-sixteenth-inch asbestos board. This left the other side clear, except at edges, for supporting the copper plates.

The copper plates are heated in this way to a temperature just below the melting point of the solder used, and the job is completed in the usual way with a heated soldering iron. It is necessary to scrape the nickel-plated surface down to the copper plate to insure a good thermal contact. This should be cleaned with a solution, say, of zinc chloride, any excess of which should be 


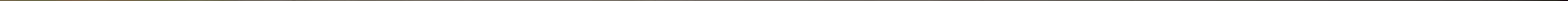


removed later by swabbing with water. The excess solder should be trimmed down with a sharp tool, for the wires and junctions should not interfere materially with the flat assembly of the parts. These wires should then be inserted in narrow, thin cloth tubes (silk or balloon cloth) and shellacked to the plates in the positions indicated on the drawings (fig. I). Where a wire crosses from center to guard plate, withhold shellacking of this portion until assembling.

2. Balsa wood mount board. -The balsa wood board should be flat and fairly homogeneous and reinforced at the end grain edges with metal strips, as shown in Figure $\mathrm{I}$. The recessed portions should be prepared to accurate dimensions and finished to the uniform depth of $0.47 \mathrm{~cm}$, or $13 / 16$ inch. This depth is selected to allow the parts assembled therein to protrude just slightly above the top plane of the board, so the specimens mounted there will be in firm contact. The recess can be uniformly cut by using a narrow-blade grooving plane operated with the grain of the wood and supported by guiding strips, which help to regulate the uniformity of depth of cut. If the full depth of cut is made by several depth adjustments of the plane, the job will finish to a uniform depth. The next operation on this board is to cut narrow grooves according to detail locations shown in Figure I for accommodating the thermocouple and power lead wires. These extend from the recess edge to the outer edge of the balsa board, where they are to be connected later to binding posts and the selector switches. Next attach the clamping bolts, binding posts, and selector switches to the board in location shown in Figure I.

3. Micanite sheets and resistance grids.-The location of micanite electric insulating sheets and grid cores are indicated in a magnified detail in Figure $\mathrm{I}$, also in Figure 5. Four full-sized sheets are used between the copper plates and the resistance grids. Two full-sized sheets are cut to the exact dimensions of the central and guard plates. These latter sheets serve as cores, about which the resistance ribbon is wound to form the four heating grids. The layout of the grid winding is given in Figure $\mathrm{I}$, and a photograph of a finished set (center and guard) is shown in Figure 2.

The layout of the micanite sheets and cutting to dimensions can best be accomplished by the use of a razor blade, which may be mounted in a handle for convenience. This tool is also useful 
for cutting grooves in the balsa wood and for trimming and scraping where required.

In winding the resistance ribbon about the cores care should be taken to wind with uniform spacing, to finish flat, and to keep edges straight, so that the best possible alignment with the cover plates will be obtained. In bending the winding about the edge of the core good results can be obtained by pressing the bend with the fingers and locating it accurately in accordance with the space

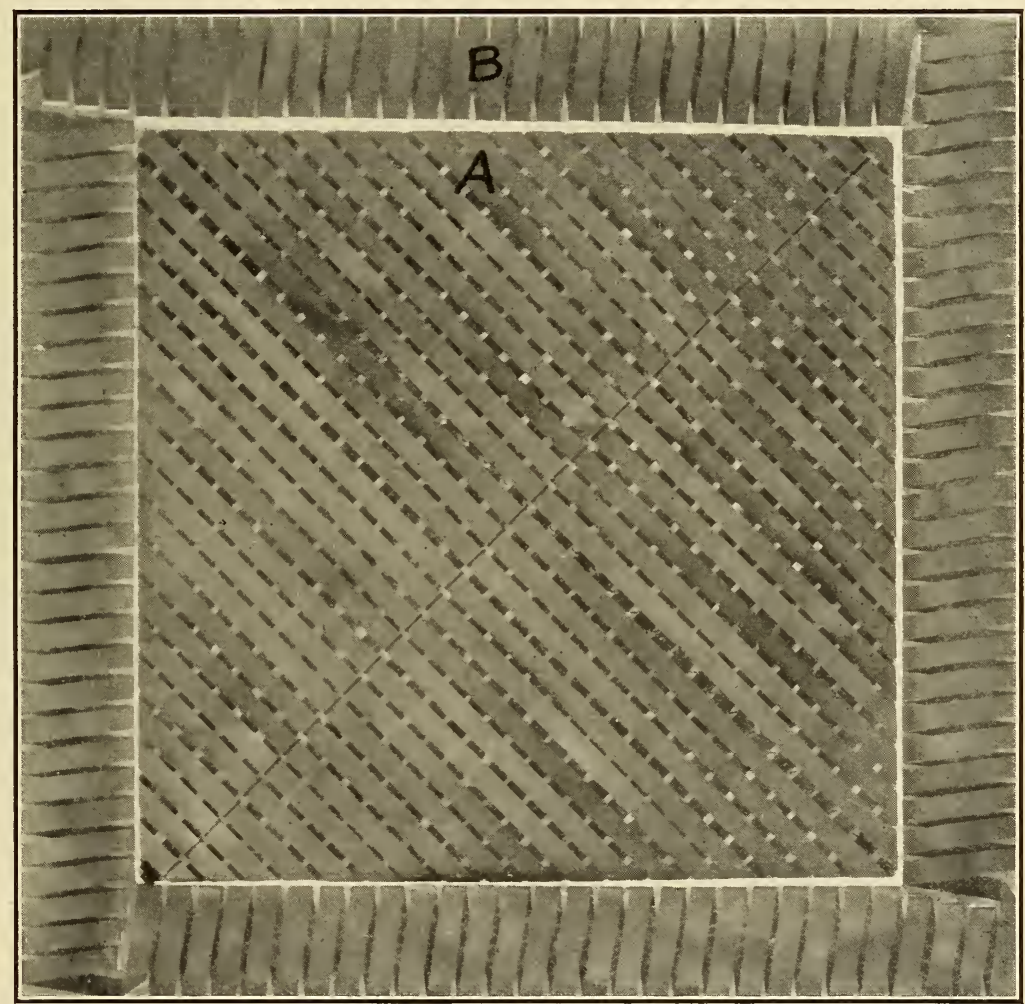

FIG. 2.-Heating grid: Resistance ribbon wound about an electric insulating core

marks laid out on the edge of the cores. (See layout dimensions accompanying grids in table, fig. I.) The bends may be finished with a small pair of flat-nose pliers, which operation helps to hold each bend in place. The terminals of the four resistance grids should be finished similarly to that shown in Figure I (corner detail) and copper lead wires of sufficient length soldered at the edge of each terminal.

Next, the construction holes indicated in Figure I for each grid should be located between the crisscross windings. The edges of 
the resistance ribbon adjacent to the holes should be very carefully insulated by cutting local $\mathrm{V}$ notches, and insulating with a lap of cloth and shellac. These holes will be referred to later and are used to pass construction screws which extend from top copper plate to bottom copper plate. The windings should be carefully insulated from these screws.

4. Accessories and other standard equipment.-Constructional details for the several accessory parts and the location of the same are given in Figure I. These parts are as follows: Wood supporting frame, bearings for rotating the mount board, edge extensions for holding rollers used in loading specimens, clamping strips for securely mounting specimens, selector switches, and a thermocouple fork for carrying a thermocouple at its end for obtaining temperature at the top of mounted specimens. Any other essential equipment for operating is considered standard and may be obtained generally from the manufacturers of such articles, such as thermocouple cold-junction ice box, rheostats, storage battery, potentiometer and its accessories, etc. These items are shown in the photograph (fig. 6).

5. Construction details.-It is necessary to align the holes made in the resistance grids, which have been referred to in 3 , with similar holes in the other parts. The inside plates require a slightly smaller hole and must be threaded, while the holes in the micanite sheets and top plates must be a little larger to pass the small construction screws. The holes in the top plate must be countersunk to accommodate the bevel of the flat-head screws. It is necessary to drill and countersink four extra holes in the inside plates for attaching these plates to the mount board. The screws selected should be flat-head shorts so as not to extend above or touch plates on the reverse side of board. These should not be screwed in so tight as to pull out from the very soft balsa wood.

(b) Assembly.- With all the parts properly prepared and identified, and with the power and thermocouple wires extending in the right directions and labeled it is relatively easy to assemble the parts in their proper sequence and make the necessary connections to power binding posts and selector switches. If too much trouble is anticipated or experienced due to handling the top central and guard plates which are not rigidly connected, but must be handled together to keep from breaking the short differential couple wires, it may be necessary to resort to an alternative detail, as follows: This consists simply of a firm mechanical attachment of the dif- 
ferential wires on the outside of the plates after they are otherwise assembled. A choice between the inside soldered connection or the outside mechanical connection might be made to advantage at the start.

In assembling, true alignment of parts, as well as positive electrical insulation where designated, must be had and the top plates should finish as flat as possible. Some little adjustment can be made by changing tightness of the small construction screws.

After the assembly of the parts is completed, it is advisable to shellac a strip of cloth and paste it at the edge of the recess in the balsa-wood board, allowing it to overlap the edges of the guard plate and the balsa wood. This strip holds the assembled parts more securely to the mount board and also cuts down undesirable air leakage at this edge.

\section{SPECIFICATIONS FOR OPERATION}

\section{WIRING DIAGRAM (APPARATUS AND ACCESSORIES)}

Figure 3 consists of diagrams of the several parts of the apparatus and accessories used in furnishing and controlling the electric power and measuring the temperatures resulting at the heat distributing plates. The temperatures are measured by thermocouples in terms of emf (electromotive force) on a potentiometer. In like manner the current measurements incident to the four independent heating circuits may be obtained from drop in potential across a standard o.or ohm resistance which may be switched into the respective circuits. An ammeter is also provided for rough current readings during adjustments.

\section{MANIPULATION OF POWER, THERMOCOUPLE, AND POTENTI- OMETER CIRCUITS}

The diagram is labeled so that it may be followed readily, but a brief explanation may be in order. Primarily there are three sets of circuits, viz, I, power; 2, thermocouple; and 3, potentiometer. The power circuit has two sources of supply, i Io volts, ac. stepped down through a transformer to Io or 20 volts, and a I 2-volt storage battery connected to a lamp bank and dc. source for the purpose of recharging. The low voltage ac. source is used only for preliminary heating of the resistance grids, while the battery is used because of its constant voltage supply for final heating to the temperature balance required during tests. The lead wires and notes in the diagram will show how the current 
is furnished and controlled in the four separate resistance grids. From the notes and similarity of size and shape of the center and edge residence grids, and the copper heat-distributing plates, the assembly of these parts in the apparatus can be easily understood. A set of grids supplies heat to an outside and inside set

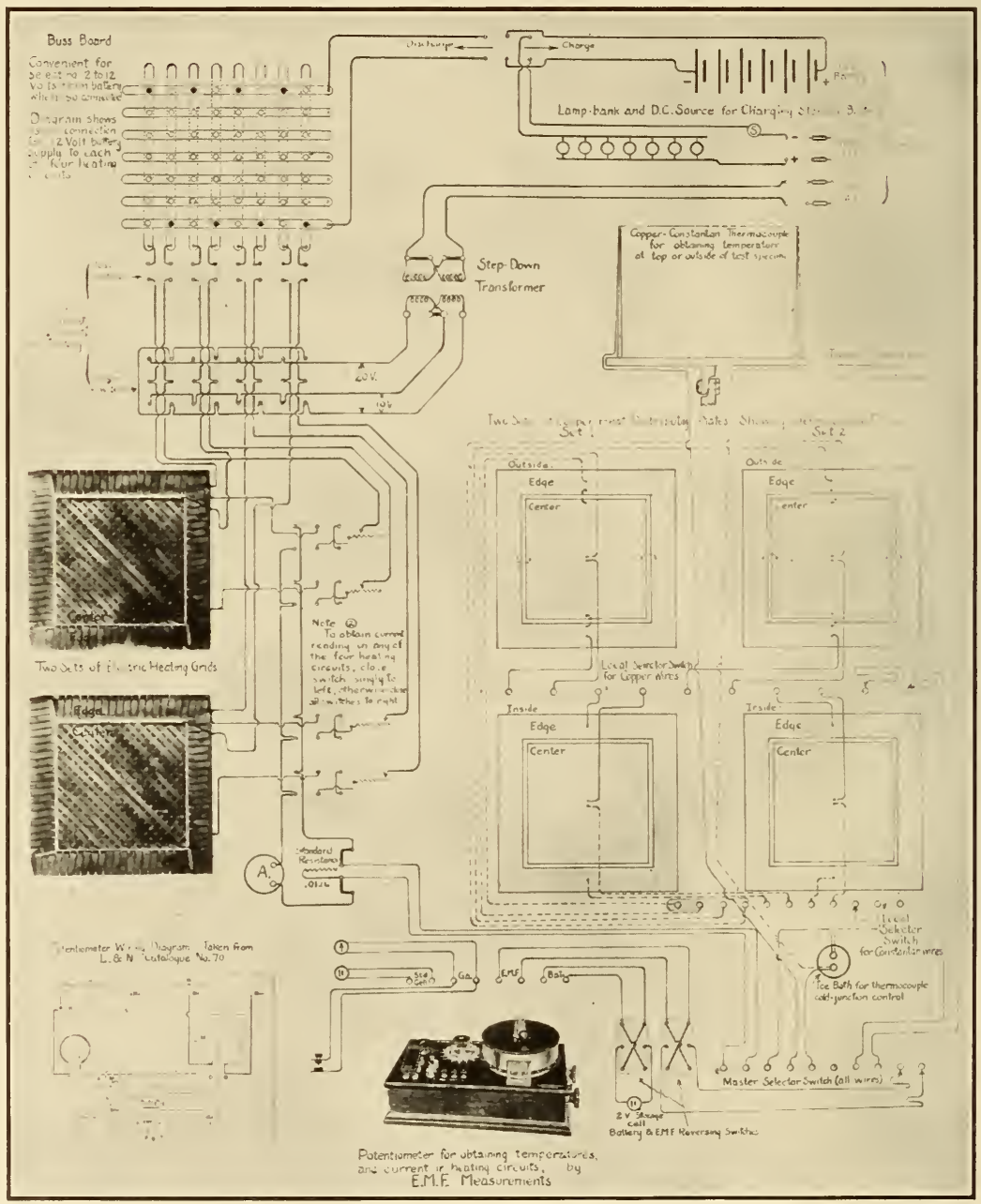

FIG. 3.-Diagrammatic wiring diagram: For heating and temperature control of the heat transmission apparatus

of plates, between which it is placed. This assembly is termed a heater set. Parts for two of these sets are shown in the diagram. When this assembled, the copper plates conduct the heat from the grids and distribute it uniformly.

The resulting temperatures of the plates are measured by thermocouples attached thereto and distributed as indicated in 
the diagram. This series of copper plates, thermocouple wires, and the local and master selector switches, also diagrammatically illustrated, form the thermocouple circuits. By means of the selector switches, the individual temperature circuits can be closed, one at a time, and the emf indication read on the potentiometer.

The potentiometer circuit or wiring diagram is shown in the lower left corner of Figure 3. This is so thoroughly explained in the maker's catalogue of this instrument that the reference (L. \& N. Cat. No. 70) only will be given here. Any equivalent potentiometer would serve the purposes as well in these measurements. It will possibly be sufficient here to define, simply, a potentiometer as follows: It is a device for measuring emf (electromotive force) differences, by either totally or partially balancing the unknown or outside emf against a variable potential difference, the value of which is known by reference to a standard of electromotive force. If the two potential differences are exactly balanced, we have the usual "null" potentiometer; if partially balanced, the deflection of the galvanometer attached gives a measure of their difference, and we have a deflection potentiometer. The "null" method is recommended here for simplicity.

\section{AN EXAMPLE OF THE TEMPERATURE BALANCE REQUIRED FOR TESTS}

\section{TYPICAL DATA REQUIRED}

Table 1.-Typical Data Required

[Heat transmission data taken during test on blanket $\mathrm{X}$ ]

[Emf (electro motive force) readings on this sheet are in milivolts]

(A) EMF READINGS BY POTENTIOMETER $v$. TIME

\begin{tabular}{|c|c|c|c|c|c|c|c|c|c|}
\hline \multirow{2}{*}{ Set.......... } & \multicolumn{3}{|c|}{ Bottom } & \multicolumn{3}{|c|}{ Top } & \multirow{2}{*}{$\begin{array}{l}\text { Bottom } \\
\text { O. S. }\end{array}$} & \multicolumn{2}{|c|}{ Top } \\
\hline & O. S. C. & I. S. E. & I. S. C. & I. S. E. & I. S. C. & O.s. C. & & O. S. & Top \\
\hline Circuit.. & $1^{\prime}-1^{\prime}$ & $2^{\prime}-2^{\prime}$ & $3^{\prime}-3^{\prime}$ & $5^{\prime}-5^{\prime}$ & $6^{\prime}-6^{\prime}$ & $7^{\prime}-7^{\prime}$ & $1^{\prime}-4^{\prime}$ & $7^{\prime}-9^{\prime}$ & \\
\hline $\begin{array}{l}\text { Time } \\
1.15 \ldots \ldots \ldots \\
1.25 \ldots \ldots \\
1.33 \ldots \ldots \\
1.40 \ldots \ldots\end{array}$ & $\begin{array}{l}1.415 \\
1.414 \\
1.410 \\
1.407\end{array}$ & $\begin{array}{l}1.493 \\
1.478 \\
1.458 \\
1.448\end{array}$ & $\begin{array}{l}1.477 \\
1.478 \\
1.467 \\
1.460\end{array}$ & $\begin{array}{l}1.507 \\
1.485 \\
1.463 \\
1.452\end{array}$ & $\begin{array}{l}1.490 \\
1.482 \\
1.463 \\
1.454\end{array}$ & $\begin{array}{l}1.432 \\
1.428 \\
1.410 \\
1.402\end{array}$ & $\begin{array}{c}0.0 \\
\cdots \ldots \\
-.008\end{array}$ & $\begin{array}{c}+0.005 \\
\cdots \ldots \\
.0 .2 .\end{array}$ & $\begin{array}{l}1.058 \\
1065 \\
1.067 \\
1.055\end{array}$ \\
\hline $\begin{array}{l}1.45 \ldots \ldots \ldots \\
1.55 \ldots \ldots \ldots \\
2.10 \ldots \ldots \\
2.20 \ldots \ldots\end{array}$ & $\begin{array}{l}1.400 \\
1.392 \\
1.387 \\
1.382\end{array}$ & $\begin{array}{l}1.443 \\
1.432 \\
1.427 \\
1.419\end{array}$ & $\begin{array}{l}1.457 \\
1.447 \\
1.438 \\
1.428\end{array}$ & $\begin{array}{l}1.446 \\
1.437 \\
1.428 \\
1.421\end{array}$ & $\begin{array}{l}1.448 \\
1.443 \\
1.429 \\
1.423\end{array}$ & $\begin{array}{l}1.397 \\
1.392 \\
1.382 \\
1.373\end{array}$ & $\begin{array}{r}.009 \\
.010 \\
-.012 \\
\ldots . .6 .\end{array}$ & $\begin{array}{l}.0 \\
.0 \\
.0 \\
. . .\end{array}$ & $\begin{array}{r}1.068 \\
1.058 \\
1.057 \\
\ldots .\end{array}$ \\
\hline $\begin{array}{l}2.33 \ldots \ldots \\
2.40 \ldots \ldots \\
2.45 \ldots \ldots \\
2.59 \ldots \ldots\end{array}$ & $\begin{array}{l}1.373 \\
1.375 \\
1.377 \\
1.371\end{array}$ & $\begin{array}{l}\text { 1. } 420 \\
\text { 1. } 418 \\
\text { 1. } 420 \\
1.418\end{array}$ & $\begin{array}{l}1.424 \\
1.423 \\
1.422 \\
1.419\end{array}$ & $\begin{array}{l}1.423 \\
1.420 \\
1.420 \\
1.419\end{array}$ & $\begin{array}{l}1.423 \\
1.422 \\
1.420 \\
1.419\end{array}$ & $\begin{array}{r}1.373 \\
1.371 \\
1.371 \\
11.370\end{array}$ & $\begin{array}{l}-.007 \\
-.004 \\
-.003 \\
-.003\end{array}$ & $\begin{array}{l}.0 \\
.0 \\
.0 \\
.0\end{array}$ & $\begin{array}{r}1.052 \\
11.058\end{array}$ \\
\hline
\end{tabular}


Table 1.-Typical Data Required-Continued

(B) CURRENT READINGS BY POTENTIOMETER $v$. TIME

\begin{tabular}{|c|c|c|c|c|}
\hline Position.... & $\begin{array}{l}\text { Bottom } \\
\text { center }\end{array}$ & $\begin{array}{l}\text { Bottom } \\
\text { edge }\end{array}$ & $\begin{array}{c}\text { Top } \\
\text { center }\end{array}$ & $\begin{array}{l}\text { Top } \\
\text { edge }\end{array}$ \\
\hline 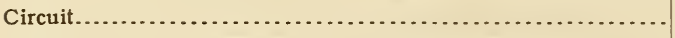 & No. 1 & No. 2 & No. 3 & No. 4 \\
\hline $\begin{array}{l}\text { Time } \\
1.35 \\
2.05 \\
2.38 \\
2.58 \ldots \ldots\end{array}$ & $\begin{array}{l}1.0413 \\
1.0402 \\
1.0611 \\
1.0601\end{array}$ & $\begin{array}{r}0.7513 \\
.7507 \\
.7427 \\
.7427\end{array}$ & $\begin{array}{l}1.0938 \\
1.0934 \\
1.1162 \\
1.1157\end{array}$ & $\begin{array}{r}0.8577 \\
.8577 \\
.8756 \\
1.8752\end{array}$ \\
\hline
\end{tabular}

1 The temperature equivalent for the emf data marked with a superior 1 in part $\mathrm{A}$ of this table, and the current reading so marked are listed below Part B of the table with the remaining data noted in computations.

Atmospheric conditions, 65 per cent relative humidity, $21.1^{\circ} \mathrm{C}$. $\left(70^{\circ} \mathrm{F}\right.$.); emf readings in millivolts. Thickness of specimen $(d)=0.71 \mathrm{~cm}(0.28$ in. $) t=36.1^{\circ}$ C. $\left(97^{\circ} \mathrm{F}\right.$.). $J=4.183$ electrical equivalent of heat. $t_{1}=28.2^{\circ}$ C. $\left(82.8^{\circ}\right.$ F. $) . \Omega=6.62 \mathrm{ohms}$ resistance, constant for the instrument. $t-t_{1}=7.9^{\circ} \mathrm{C} .\left(14.2^{\circ} \mathrm{F}.\right)$.
$I=0.8752$.

COMPUTATION IN METRIC UNITS

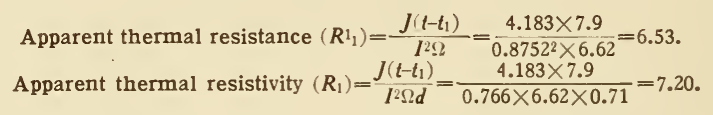

\section{DISCUSSION OF MEASUREMENTS}

Table I illustrates the number and location of temperature and current readings usually taken during a typical run on a test blanket, and other data required for computations. Emf readings are recorded against time for each of the nine thermocouple circuits and each of the four heating circuits. These are taken on a potentiometer and the equivalent temperature may be obtained readily from a calibration chart (temp. $v$. emf) for the thermocouple circuits, while the equivalent current in amperes for the heating circuits is given direct by the measured drop in potential across a o.or ohm standard resistance. In the latter measurement current $I=\frac{E}{R}=\frac{\text { emf }(\text { volts })}{\text { O.OI }(\mathrm{ohm})}=$ amperes with the decimal properly located.

The columns in the table are labeled to designate the number of the circuit, the location of which may be known by reference to Figure 5, where the lead wires are shown connected to the several heat distributing plates. The location of the measurements is further designated by a combination of the letters O. S., I. S., C., E., meaning outside, inside, center, and edge, respectively. The final readings which are starred in the table are the only ones used in calculations, an example of which is included at the bottom of the table.

The purpose of so many temperature measurements shown in the table is to indicate which electrical heating circuits require current adjustments to give, finally, a like temperature for top I. S. C. and bottom I. S. C. circuits, and a zero reading for temperature difference circuits (O. S. top and bottom C. to E.). The 
data show balances between other circuits as well, but this condition, though desirable, is not usually obtainable nor is it required. It is difficult to state what deviation from balance is permissible, so the best procedure is to aim for a perfect balance.

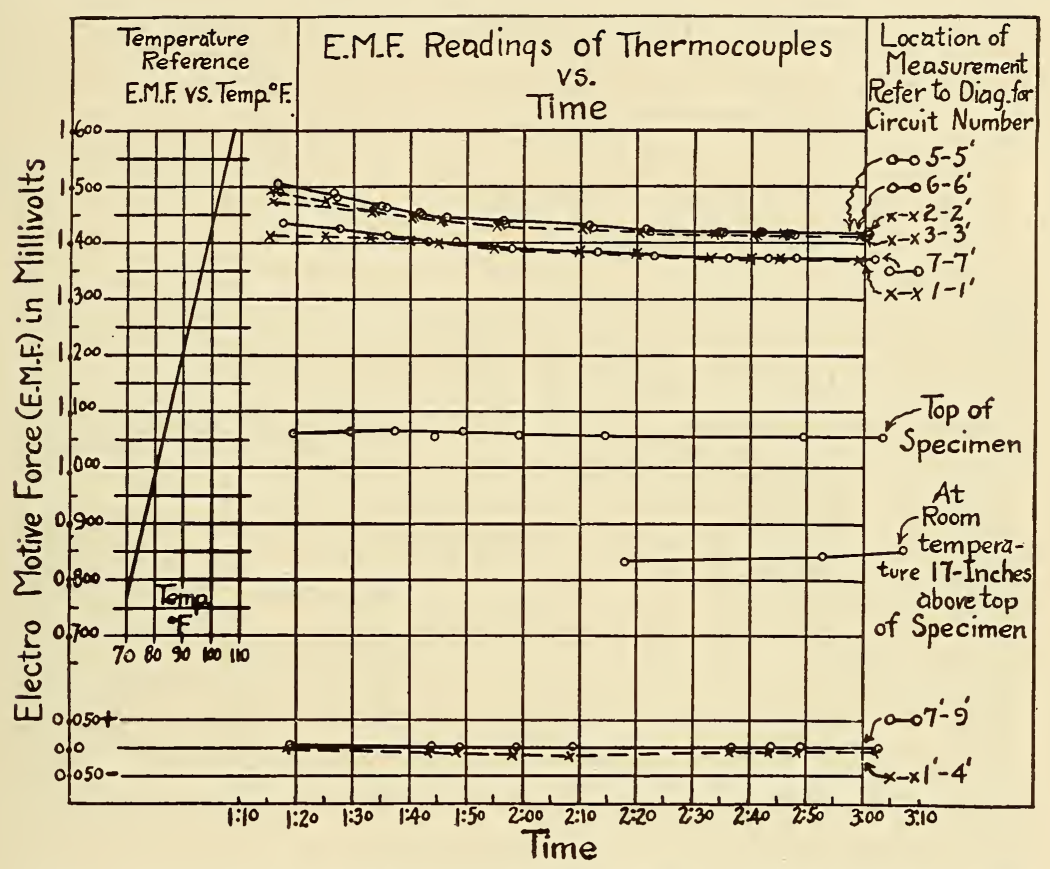

FIG. 4.-Plot of data contained in Table I (emf readings of thermocouples v. time)

In Figure 4 the temperature data have been plotted against time and show that one to two hours are usually required to bring the several parts to a temperature balance. Note the gradual

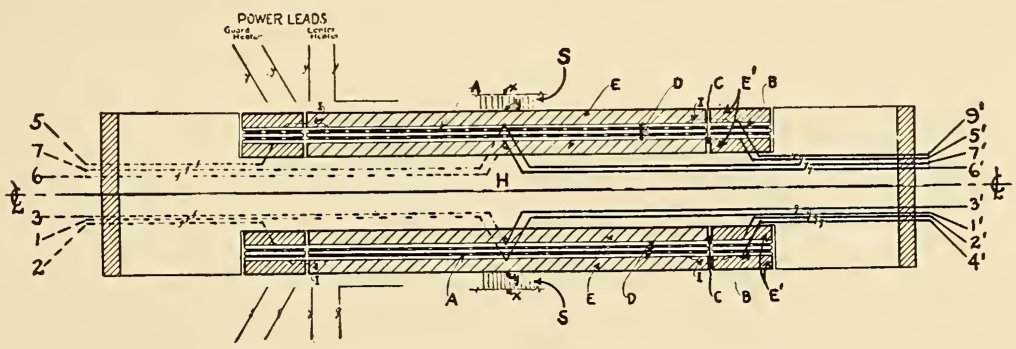

FIG. 5.-Cross section showing location of thermocouple circuits for the independently controlled heating circuits

trend of the curves to a horizontal position, which indicates uniform temperature. Note also the merging of several of the curves, which indicates temperature balance between those circuits. Refer to Figure 5 for the circuit locations. The data sheet 
serves the purpose of the chart to an experienced operator, so it is usually unnecessary to plot the data.

It is only after such a temperature balance is obtained that one can be assured that the heat dissipated in the top center heater is guarded from escape at the edges and bottom of the test section and that this heat will flow totally in one direction, viz, perpendicularly through the top test specimen, which covers the center heat distributing plate.

The apparatus is shown in Figure 6, with its accessories and with a test blanket mounted in position. The accessories referred

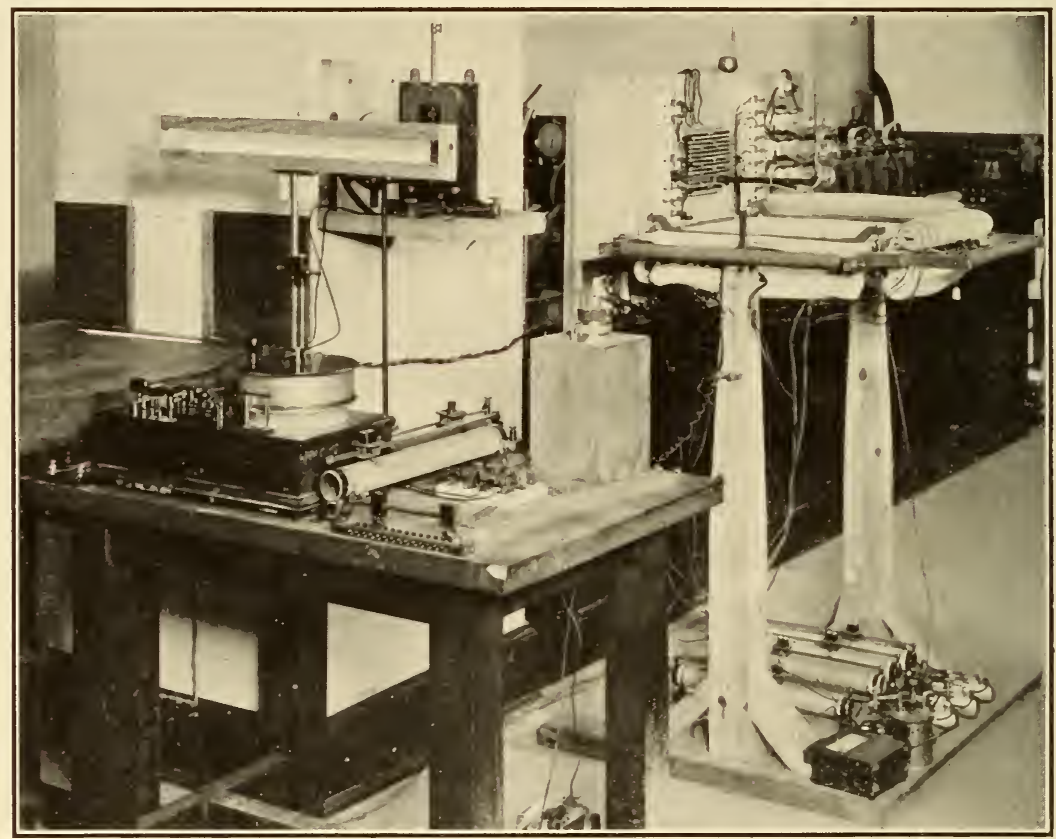

FIG. 6.-General view of the heat transmission apparatus and accessories, with test blanket mounted

to in the starred note at bottom of "bill of materials" of Figure I may be seen generally in this photograph.

\section{CONCLUSION}

From the details of construction given in Figure I, apparatus similar to that used at the Bureau of Standards for testing the heat insulating value ("thermal resistance") of textile fabrics may be constructed.

The alternative plan mentioned under the heading "assembly" provides for outside mechanical attachment of the short differ- 
ential thermocouple wires. It is believed that this change will improve the facility in assembling and allow easy repair, should such be necessary. However, this change of detail should not be considered an improvement on the standard soldered connection as indicated in Figure $\mathrm{I}$.

Since the dependability of the apparatus relies largely upon the care exercised in its construction and operation, the specifications contain explicit instructions under these headings.

Precise methods are generally required for making heat measurements, therefore, typical test data have been presented. These show the necessity for manipulating for a very good temperature balance before taking the final test data used in subsequent computations.

Washington, June io, 1924. 